\title{
Complex Rupture of an Immature Fault Zone: A Simultaneous Kinematic Model of the 2019 Ridgecrest, CA Earthquakes
}

\author{
D. E. Goldberg ${ }^{1}$, D. Melgar ${ }^{1}$, A. M. Thomas ${ }^{1}$, V. J. Sahakian ${ }^{1}$, X. Xu ${ }^{2}$, J. Geng ${ }^{3}$, B. W. Crowell ${ }^{4}$ \\ ${ }^{1}$ Department of Earth Sciences, University of Oregon, Eugene, Oregon, USA. ${ }^{2}$ Institute of Geophysics \\ and Planetary Physics, Scripps Institution of Oceanography, University of California San Diego, La Jolla, \\ California, USA. ${ }^{3}$ GNSS Center, University of Wuhan, Wuhan, China. ${ }^{4}$ Department of Earth and Space \\ Sciences, University of Washington, Seattle, Washington, USA. \\ Corresponding author: Dara E. Goldberg (ㅁoldber@uoregon.edu)
}

This is a non-peer reviewed pre-print submitted to EarthArXiv. This paper has been submitted to Geophysical Research Letters for review. 


\begin{abstract}
The July 4, $2019 \mathrm{M}_{\mathrm{w}} 6.4$ and subsequent July 6, $2019 \mathrm{M}_{\mathrm{w}} 7.1$ Ridgecrest Sequence earthquakes ruptured orthogonal fault planes in the Little Lake Fault Zone, a low slip rate $(1 \mathrm{~mm} / \mathrm{yr})$ dextral fault zone in the area linking the Eastern California Shear Zone and Walker Lane. This region accommodates nearly one fourth of plate boundary motion and has been proposed to be an incipient transform fault system that could eventually become the main tectonic boundary, replacing the San Andreas. We investigate the rupture process of these events using a novel simultaneous kinematic slip method with joint inversion of high-rate GNSS, strong motion, GNSS static offset, and InSAR data. We model the Coulomb stress change to evaluate how the first mainshock may have affected the second. Our findings suggest complex interactions between several fault structures, including dynamic and static triggering, and provide important context for regional seismic source characterization and hazard models.
\end{abstract}

\title{
Plain Language Summary
}

The San Andreas is a right-lateral strike-slip fault marking the main tectonic boundary between the North American and Pacific Plates. East of the San Andreas, a diffuse region of right-lateral shear known as the Eastern California Shear Zone (ECSZ) accommodates roughly one-quarter of the motion between the two tectonic plates. The ECSZ has been proposed to be an immature fault system that in the future will accommodate a greater portion of the region's tectonic forces, coalesce into a simple, throughgoing fault, and eventually replace the San Andreas as the major tectonic boundary. The July 2019 Ridgecrest sequence therefore provides the opportunity to gain valuable insights into the development of tectonic boundaries. We analyze the spatial and temporal history of slip during the two largest events in the sequence, the July $4 \mathrm{M}_{w} 6.4$ and July $6 \mathrm{M}_{w} 7.1$ earthquakes, and demonstrate a novel approach to evaluate seismic and geodetic observations for both earthquakes simultaneously. We identify complex interactions between discrete fault segments, including dynamic triggering of one fault by slip on another, and present evidence for static triggering of the July $6 M_{w} 7.1$ event by the July $4 M_{w} 6.4$ earthquake.

\section{Introduction}

The Ridgecrest Sequence earthquakes ruptured the Little Lake Fault Zone, a low slip-rate (1 mm/yr) region dominated by northwest striking, dextral strike-slip faulting linking the Eastern California Shear Zone (ECSZ) and Walker Lane (Figure 1). The area is located on the western edge of the Basin and Range province and bounded by Garlock Fault and Mojave Block to the south. To the west, the San Andreas Fault (SAF) is the main tectonic boundary between the Pacific and North American Plates. The SAF has a long history of stepping inland [Atwater \& Stock, 1998], transferring the tectonic motion eastward over time. The Walker Lane/ECSZ currently accommodates $9-23 \%$ of the total relative plate motion between the Pacific and North American Plates [Dokka \& Travis, 1990]. It has been proposed that in the future, this diffuse region may coalesce into a major transform boundary and assume the bulk of the tectonic motion presently accommodated by the SAF [Faulds et al., 2005]. The study region is therefore an example of an immature fault system in an early stage of development. Hence, the interaction between the 2019 July 4 $\mathrm{M}_{\mathrm{w}} 6.4$ and July $6 \mathrm{M}_{\mathrm{w}} 7.1$ earthquakes provides important context for the development of major tectonic boundaries and the future regional seismic hazard.

The July $4 \mathrm{M}_{\mathrm{w}} 6.4$ earthquake occurred on northeast-trending faults, roughly $20 \mathrm{~km}$ north of the Garlock Fault. The surface trace suggests that rupture crossed a $1.3 \mathrm{~km}$ stepover directly to the south of the epicenter 
(Figure 1). The subsequent July $6 \mathrm{M}_{\mathrm{w}} 7.1$ earthquake occurred 34 hours later and ruptured perpendicular to the former, along a northwest-trending series of faults, arresting at the Garlock Fault. The rupture process for both events is spatially and temporally complex, including several discontinuous fault planes in addition to the delay between events.

The close spatial and temporal spacing of the two Ridgecrest mainshocks naturally raises questions about potential interaction between the two events. Earthquakes relieve stress accumulated by tectonic processes, yet cause a heterogenous redistribution of regional stress that can increase stress on a local scale, pushing certain faults closer to seismic failure. Faults that are brought to failure in part due to the local stress change caused by another earthquake are said to be statically triggered; the initial earthquake either reduces the effective normal stress clamping the fault or increases the shear stress that promotes failure [e.g. Freed, 2005]. Coulomb static stress change calculations have been used to explain earthquake sequences in eastern and southern California, including another Mojave-area sequence that began in April 1992 with the $M_{w} 6.1$ Joshua Tree earthquake, followed two months later by the June $1992 \mathrm{M}_{\mathrm{w}} 7.3$ Landers and $\mathrm{M}_{\mathrm{w}} 6.3$ Big Bear earthquakes, which were separated by just three hours [King and Cocco, 2001]. In another triggering mechanism, rupture that initiates due to stress change from the passage of seismic waves associated with an earlier earthquake is said to be dynamically triggered. Near-field dynamic stress transfer has been observed to allow rupture to jump across fault segments separated by as much as $5 \mathrm{~km}$ [Freed et al., 2005]. Immature fault systems may exhibit dynamic triggering more frequently than mature fault boundaries because they consist of families of disconnected structures, rather than having well organized throughgoing faults [e.g. Gomberg, 1996].

The rupture kinematics in immature fault systems have been documented previously for earthquakes in the ECSZ and other tectonic environments. The $2010 \mathrm{M}_{\mathrm{w}} 7.2$ El Mayor-Cucapah, at the California-Mexico border and $1999 \mathrm{M}_{\mathrm{w}} 7.1$ Hector Mine, California earthquakes both ruptured multiple fault planes, away from the main plate boundary, at relatively low rupture velocities averaging $2.5 \mathrm{~km} / \mathrm{s}$ [Wei et al., 2011] and 2.2 $\mathrm{km} / \mathrm{s}$ [Ji et al., 2002], respectively. The $1992 \mathrm{M}_{\mathrm{w}} 7.3$ Landers earthquake ruptured five distinct fault segments [Sieh et al., 1993] at an average velocity of $2.7 \mathrm{~km} / \mathrm{s}$ [Peyrat et al., 2001]. Elsewhere, the 2012 $\mathrm{M}_{\mathrm{w}}$ 8.6 Wharton Basin sequence ruptured six young oceanic faults [Yue et al., 2012] at speeds between 1.5 and $2.5 \mathrm{~km} / \mathrm{s}$ [e.g. Yue et al., 2012; Wei et al., 2013] and has contributed to the formation of a discrete plate boundary between the Indian and Australian plates [Hill et al., 2015]. The $2016 \mathrm{M}_{\mathrm{w}} 7.8$ Kaikoura earthquake is particularly complex, rupturing more than ten discrete faults, including both strike slip and thrust faulting motion, at low rupture velocities between 1.4 and $2.0 \mathrm{~km} / \mathrm{s}$ [e.g. Cesca et al., 2017; Hollingsworth et al., 2017; Zhang et al., 2017]. This low rupture speed is likely attributable to immature faults being less compliant, more geometrically complex, and rougher than their more developed counterparts [Perrin et al., 2016]. In contrast, high rupture speeds, including sustained supershear rupture, are typically associated with well-developed faults devoid of splays or geometric complexities [e.g. Bouchon et al., 2010]. For example, the $2018 \mathrm{M}_{\mathrm{w}} 7.5 \mathrm{Palu}$, Indonesia earthquake reached supershear rupture in a well-developed fault damage zone with only large-scale fault bends [e.g. Bao et al., 2019; Socquet et al., 2019]. The $2002 \mathrm{M}_{\mathrm{w}} 7.9$ Denali, Alaska and $2001 \mathrm{M}_{\mathrm{w}} 7.8$ Kunlun, Tibet earthquakes propagated mostly unilaterally along long, simple, established faults planes at high rupture speeds of $3.2 \mathrm{~km} / \mathrm{s}$ and $3.4 \mathrm{~km} / \mathrm{s}$, respectively [Ozacar and Beck, 2004]. 
Here we investigate the spatial and temporal distributions of slip during the $M_{w} 6.4$ and $M_{w} 7.1$ mainshocks. We will show that the events exhibit characteristics representative of an immature fault in the process of coalescing to a simple geometry. We argue that both dynamic triggering — within faults that ruptured during the initial $M_{w} 6.4$ earthquake - and static triggering of the $M_{w} 7.1$ earthquake by the $M_{w} 6.4$ rupture, likely occurred. We demonstrate a novel simultaneous kinematic slip inversion methodology that allows us to use Interferometric Synthetic Aperture Radar (InSAR) data that spans both earthquakes along with seismic (strong-motion accelerometer) and geodetic (high-rate Global Navigation Satellite Systems, HR-GNSS)

datasets that recorded each earthquake separately. In our new approach, we use these different datasets to solve for the kinematic slip model of both events concurrently, in a single inversion step.

\section{Data}

The kinematic slip inversion considers several distinct observational datasets. First, we select 12 strong motion and 12 GNSS sites based on proximity and azimuthal coverage of the two earthquakes (Figure 1). We include static offsets estimated by the Nevada Geodetic Laboratory (geodesy.unr.edu) as well as highrate $(5 \mathrm{~Hz})$ GNSS displacements from the Network of the Americas (unavco.org) post-processed using precise point positioning [Geng et al., 2019] to achieve centimeter-level precision in the horizontal components and $\sim 3 \mathrm{~cm}$ precision in the vertical direction [Melgar et al., 2019]. We lowpass filtered the HR-GNSS waveforms with a corner frequency of $0.5 \mathrm{~Hz}$. We integrate strong-motion acceleration waveforms from the Southern California Seismic Network (scedc.caltech.edu) to velocity, and bandpass filter between 0.05 and $0.5 \mathrm{~Hz}$. Finally, we use InSAR line of sight (LOS) measurements from two acquisitions of the Sentinel-1 satellites operated by the European Space Agency. For ascending track 64 (Figure 1) and descending track 71 (Figure S1), the interferometric pairs span the dates 2019/07/04 to 2019/07/10 and 2019/07/04 to 2019/07/16, respectively. The Sentinel-1 data processing techniques [Chen \& Zebker, 2002; Lohman \& Simons, 2005; Sandwell et al., 2016; Xu et al., 2016, 2017] are summarized in Text S1. 


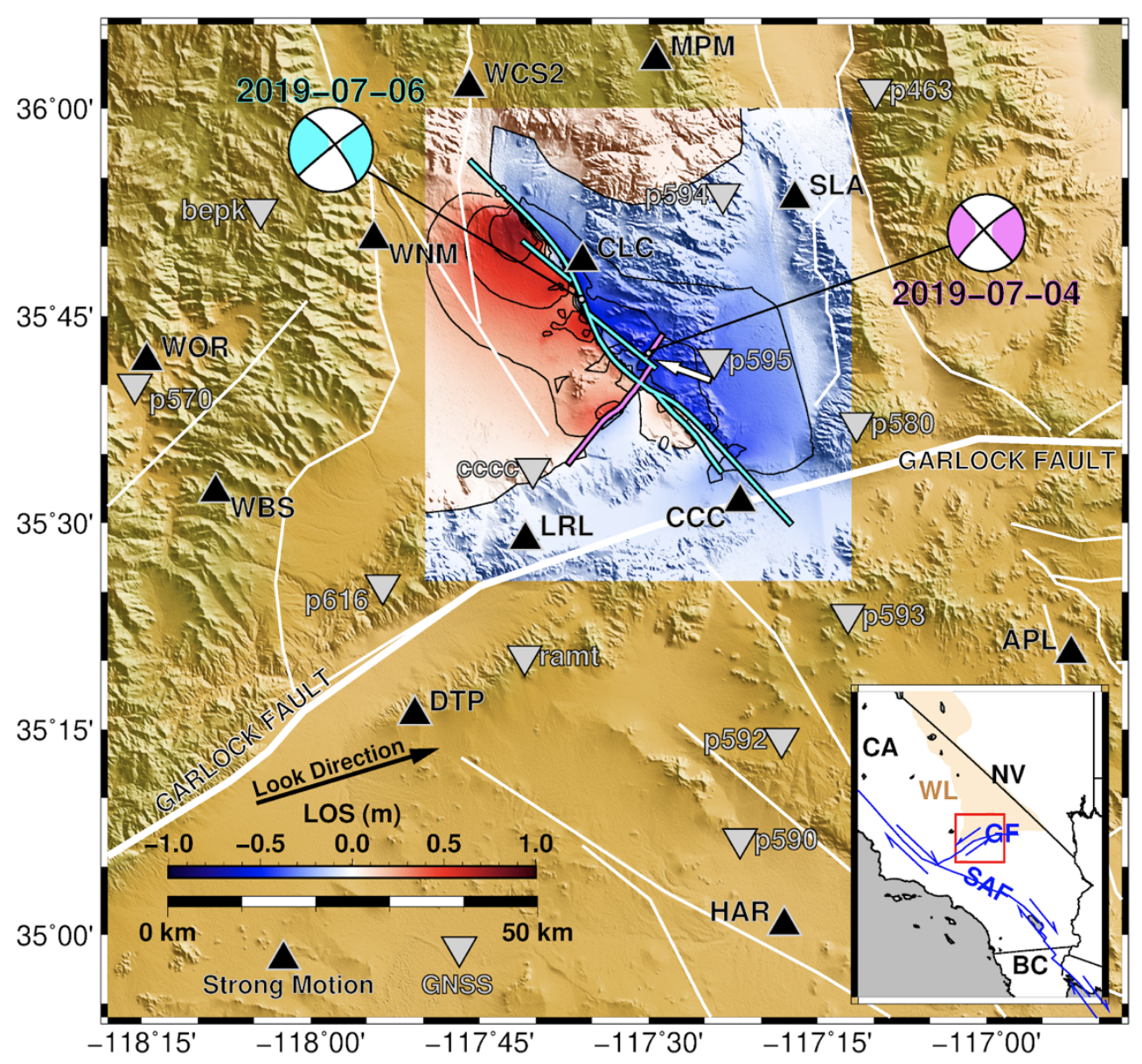

Figure 1. High-rate GNSS (grey inverted triangles) and strong motion accelerometer (black triangles) station locations. InSAR line of sight observations from Sentinel-1 ascending track 64 (look direction indicated by bold black arrow) overlain by assumed fault traces for the July $4 \mathrm{M}_{\mathrm{w}} 6.4$ and July $6 \mathrm{M}_{\mathrm{w}} 7.1$ earthquakes, in cyan and pink, respectively. Centroid moment tensor solutions for the two events (globalcmt.org) are shown in the same corresponding colors with lines connecting to their respective epicenter locations. The white arrow points to the location of a $1.3 \mathrm{~km}$ stepover in the fault structure of the July $4 \mathrm{M}_{\mathrm{w}} 6.4$ event. The inset map (bottom right) shows the regional context of the study area in California (CA), south of Nevada (NV) and north of Baja California, Mexico (BC). The dextral San Andreas Fault (SAF) passes through the southwest corner of the mapped region, with the sinistral Garlock Fault (GF) transecting the study region. The brown shaded region denotes the approximate area of the diffuse Walker Lane (WL) dextral deformation zone.

\section{Methods}

\subsection{Kinematic Slip Inversion Methodology}

We demonstrate a novel simultaneous kinematic slip inversion methodology that permits joint inversion of data types that observe just one of the two earthquakes as well as data types that include contribution from both events in a single observation. More specifically, we use static displacements, HR-GNSS displacement waveforms, and accelerometer-derived velocity waveforms, each of which observe the two mainshocks 
separately. We also use InSAR LOS measurements that include deformation from both the July $4 \mathrm{M}_{\mathrm{w}} 6.4$ and the July $6 \mathrm{M}_{\mathrm{w}} 7.1$ events in each interferometric pair. We invert these two categories of data simultaneously to estimate a kinematic slip model of the two events in a single inversion step. We use the gradient of the interferometric phase to identify discontinuities in the deformation associated with surface faulting and define six fault planes - two related to the July 4 event and four related to the July 6 event (Figure 1) - that are assumed to be vertically dipping (corroborated by the regional moment tensor solutions). Because the surface traces have a complex curvilinear geometry, the fault planes are discretized into an irregular triangular mesh with subfaults with an average area of $2.9 \mathrm{~km}^{2}$ (Figure 2). The total slip is subject to Tikhonov minimum-norm regularization, and the regularization parameter chosen is the value that results in the proper total seismic moment for the two mainshocks.

Our approach uses the multi-time window method [Ide et al., 1996] to solve for the distribution of slip in time and space (implementation described in Melgar \& Bock [2015]). We use five 50\% overlapping triangle-shaped source time functions of rise time $0.6 \mathrm{~s}$ and $1.3 \mathrm{~s}$ for the $\mathrm{M}_{\mathrm{w}} 6.4$ and $\mathrm{M}_{\mathrm{w}} 7.1$ events, respectively. This allows variability in rupture speed across the faults. From the moment tensor solutions, the primary motion of the July $4 \mathrm{M}_{\mathrm{w}} 6.4$ event is left-lateral strike-slip, while the July $6 \mathrm{M}_{\mathrm{w}} 7.1$ event motion is primarily right-lateral strike-slip. We therefore constrain the rake of the slip along the $M_{w} 6.4$ faults to be between $-45^{\circ}$ and $45^{\circ}$ from North, and the slip along the $\mathrm{M}_{\mathrm{w}} 7.1$ faults to be between $135^{\circ}$ and $225^{\circ}$ from North. We calculate green's functions using the frequency-wavenumber technique [Zhu \& Rivera, 2002]. We assume a 1-D velocity model from the Southern California Earthquake Center (SCEC) Mojave-area velocity model (Figure S2) and a maximum rupture velocity of $2.0 \mathrm{~km} / \mathrm{s}$, which is roughly 0.55 times the shear wave velocity at the hypocentral depths of the earthquakes. We performed inversions at a range of rupture velocities between 1.4 and $3.0 \mathrm{~km} / \mathrm{s}$ (see Figures $3 \mathrm{a}, \mathrm{S} 3$ ) and found $2.0 \mathrm{~km} / \mathrm{s}$ to be a mutually favored velocity for both the $\mathrm{M}_{\mathrm{w}} 6.4$ and $\mathrm{M}_{\mathrm{w}} 7.1$ events when considered independently; we prescribed that constraint to the simultaneous inversion as well. The surface trace shows that the July $4 \mathrm{M}_{\mathrm{w}} 6.4$ event ruptured two discrete fault planes across a $1.3 \mathrm{~km}$ stepover. Rather than assume that the timing of rupture across the stepover is continuous, we create a grid of potential rupture onset locations on the secondary fault to determine which location of secondary rupture initiation best fits the observational data (Figure 3a).

We prescribe weights such that each observation of the same data type has the same weight, yet there is variation between the different observation types. The final weighting was determined in part by trial and error, but was informed by both the data precision and the L2 vector norm of the data type, to ensure that one data type does not overwhelm the inversion (see description in Melgar et al. [2016]). Table S1 has the final relative weights used in the inversion.

Simultaneous inversion of the two events requires careful organization of the Green's function matrix, $\mathbf{G}$, within the inverse problem $\mathbf{d}=\mathbf{G m}$, where $\mathbf{d}$ is the observational dataset and $\mathbf{m}$ is the vector of model parameters (the slip on each subfault). In our formulation, $\mathbf{d}$ is a column vector of data ordered in the following way: July 4 static offsets, displacement waveforms, and velocity waveforms, July 6 static offsets, displacement waveforms, and velocity waveforms, InSAR LOS observations from descending track 71, and finally, from ascending track 64 . The $\mathbf{G}$ matrix must therefore properly relate each dataset to the model parameters of the relevant earthquake(s). We build separate Green's function matrices for the July 4-only and July 6-only datasets (i.e. GNSS static offsets, displacement waveforms and accelerometer-derived velocity waveforms), and for the two InSAR datasets, which are affected by the model parameters of both 
events. We concatenate these matrices to form the full $\mathbf{G}$ matrix. An example for a single time window inversion is given by Equation 1. For the multi-window case, as we have implemented here, the $\mathbf{G}$ and $\mathbf{d}$ matrix rows are simply repeated $n$ times, where $n$ is the number of windows.

$$
d=\left[\begin{array}{l}
d_{\text {static }}^{2019-07-04} \\
d_{\text {displacement }}^{2019-07-04} \\
d_{\text {velocity }}^{2019-07-04} \\
d_{\text {static }}^{2019-07-06} \\
d_{\text {displacement }}^{2019-06} \\
d_{\text {velocity }}^{2019-07-06} \\
d_{\text {InSAR-T71D }} \\
d_{\text {InSAR-T64A }}
\end{array}\right] \quad G=\left[\begin{array}{cc}
G_{\text {static }}^{2019-07-04} & 0 \\
G_{\text {displacement }}^{2019-07-04} & 0 \\
G_{\text {velocity }}^{2019-07-04} & 0 \\
0 & G_{\text {static }}^{2019-07-06} \\
0 & G_{\text {displacement }}^{2019-07-06} \\
0 & G_{\text {velocity }}^{2019-06} \\
G_{\text {InSAR-T71D }} & G_{\text {InSAR-T71D }} \\
G_{\text {InSAR-T64A }} & G_{\text {InSAR } T 64 A}
\end{array}\right] \quad m=\left[\begin{array}{l}
m^{2019-07-04} \\
m^{2019-07-06}
\end{array}\right]
$$

\subsection{Coulomb Stress Change Methodology}

We evaluate the Coulomb stress change caused by the July $4 \mathrm{M}_{\mathrm{w}} 6.4$ earthquake on the faults associated with the $M_{w} 7.1$ earthquake nearly 34 hours later, using our best fitting slip model of the $M_{w} 6.4$ event. We use the formulation of Lin \& Stein [2004] and Toda et al., [2005] for a homogeneous half-space and assume a rigidity of $36.6 \mathrm{GPa}$, a Poisson's ratio of 0.25 , and a coefficient of friction of 0.4 (see Text S2 for details).

\section{Results}

\subsection{Kinematic Slip Inversion}

The inversion estimates the seismic moment of the July 4 and July 6 events to be $4.37 \times 10^{18} \mathrm{Nm}\left(\mathrm{M}_{\mathrm{w}} 6.36\right)$ and $4.41 \times 10^{19} \mathrm{Nm}\left(\mathrm{M}_{\mathrm{w}} 7.03\right)$, respectively. Comparisons between the observed and modeled data is available in Figures S1 (InSAR), S4 (GNSS static offsets) and S5 (HR-GNSS and seismic waveforms). We note that although the InSAR residuals (Figure S1) can be improved with higher weighting (Figure S7), this results in modeled surface slip that exceeds field observations and may include postseismic deformation (Figure S8), and thus we have selected a final model which best agrees with all available observations. The respective rupture durations are $12.2 \mathrm{~s}$ and $23.8 \mathrm{~s}$ (Figure 2). The maximum moment rate of the first earthquake occurs about $60 \%$ into the rupture duration, while the larger event reaches maximum moment rate early on, at only $\sim 25 \%$ of the total rupture duration.

The July $4 \mathrm{M}_{\mathrm{w}} 6.4$ event began on a small fault segment, jumping a stepover to continue onto a larger fault plane to the southwest (Figure 1). We evaluated this earthquake independently of the second mainshock (excluding the InSAR data, which spanned both events) in order to identify how the rupture transitioned to the secondary fault in time and space. We considered the case of dynamic triggering of the secondary fault from the passing seismic waves generated from slip on the initial fault. We constructed a grid of potential rupture initiation locations along the secondary fault (Figure 3a), including an additional node at the subfault on the secondary plane closest in distance to the event hypocenter. We constrain the rupture onset times such that rupture begins on the secondary fault at the time when the S-wave from the overall event hypocenter passes the subfault of interest. We calculate the overall root-mean-square (RMS) difference between the observations and model for each of these potential initiation locations, and find that the 
preferred location for the initiation point of rupture on the secondary fault is at roughly $15 \mathrm{~km}$ depth, and 6 $\mathrm{km}$ from the fault edge nearest the event hypocenter, and with a maximum rupture velocity of $2.0 \mathrm{~km} / \mathrm{s}$ (Figure 3a). This dynamic triggering of slip on the secondary fault plane, results in dual slip pulses migrating across the two fault planes (Figure 3b). Due to our limited spatial and temporal resolution, we have tested only the case of dynamic triggering from the passing S-wave, but note that triggering from an earlier or later seismic phase would likely result in a shift in the preferred location of rupture initiation across the stepover. Our inversion uses longer period data, thus we cannot discern this clearly.

The main asperity of the July $4 \mathrm{M}_{\mathrm{w}} 6.4$ event is centered around $7 \mathrm{~km}$ depth toward the center of the secondary fault plane (Figure 2). Slip reaches $\sim 1 \mathrm{~m}$ in this location, however the maximum slip amplitude $(1.1 \mathrm{~m})$, occurs in the shallow part of the initial fault plane. Our model suggests surface offsets up to $0.8 \mathrm{~m}$ resulting from this first event. The maximum slip associated with the $M_{w} 7.1$ event reaches $\sim 4 \mathrm{~km}$ in the main asperity, which is located in the area between the $M_{w} 7.1$ hypocenter and the cross-cutting $M_{w} 6.4$ fault planes (see Figure 1). Rupture appears to be concentrated in two lobes on the throughgoing $\mathrm{M}_{\mathrm{w}} 7.1$ fault, with slip reaching $>20 \mathrm{~m}$ depth. The shorter fault segments associated with the $\mathrm{M}_{\mathrm{w}} 7.1$ mimic the patterns on the adjacent segment of the throughgoing fault plane. In order to determine whether the features exhibited in the inversion are robust, we performed a jackknife test, which shows that the locations of main asperities (Figures 2, S6) are well constrained, but our model is less certain of the shallowest slip, slip at the fault edges and below the main asperities. Details are available in Text S3 and Figure S6.
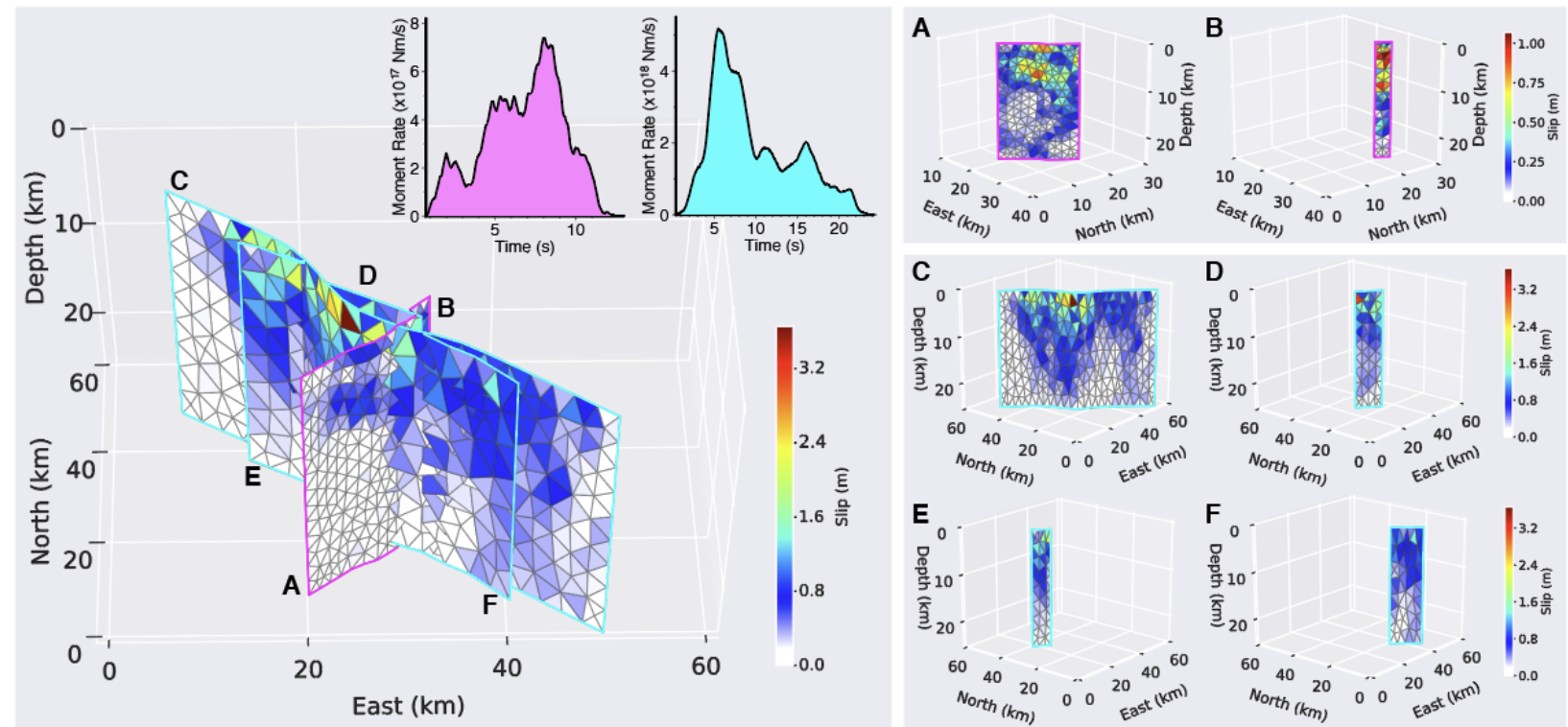

Figure 2. Slip model from joint inversion of strong motion, GNSS and InSAR observations spanning both the July $4 M_{w} 6.4$ and July $6 M_{w} 7.1$ earthquakes. Source time functions for the July 4 and July 6 events are shown in pink and cyan, respectively, in the top right inset of the full fault model. Fault segments A-B (outlined in pink) ruptured during the July $4 \mathrm{M}_{\mathrm{w}} 6.4$ earthquake, while fault segments C-F (outlined in cyan) ruptured during the July $6 \mathrm{M}_{\mathrm{w}} 7.1$ event. Note the different color scales used for the $\mathrm{M}_{\mathrm{w}} 6.4$ event (fault segments $\mathrm{A}$ and $\mathrm{B}$ ) in the top right panel. 


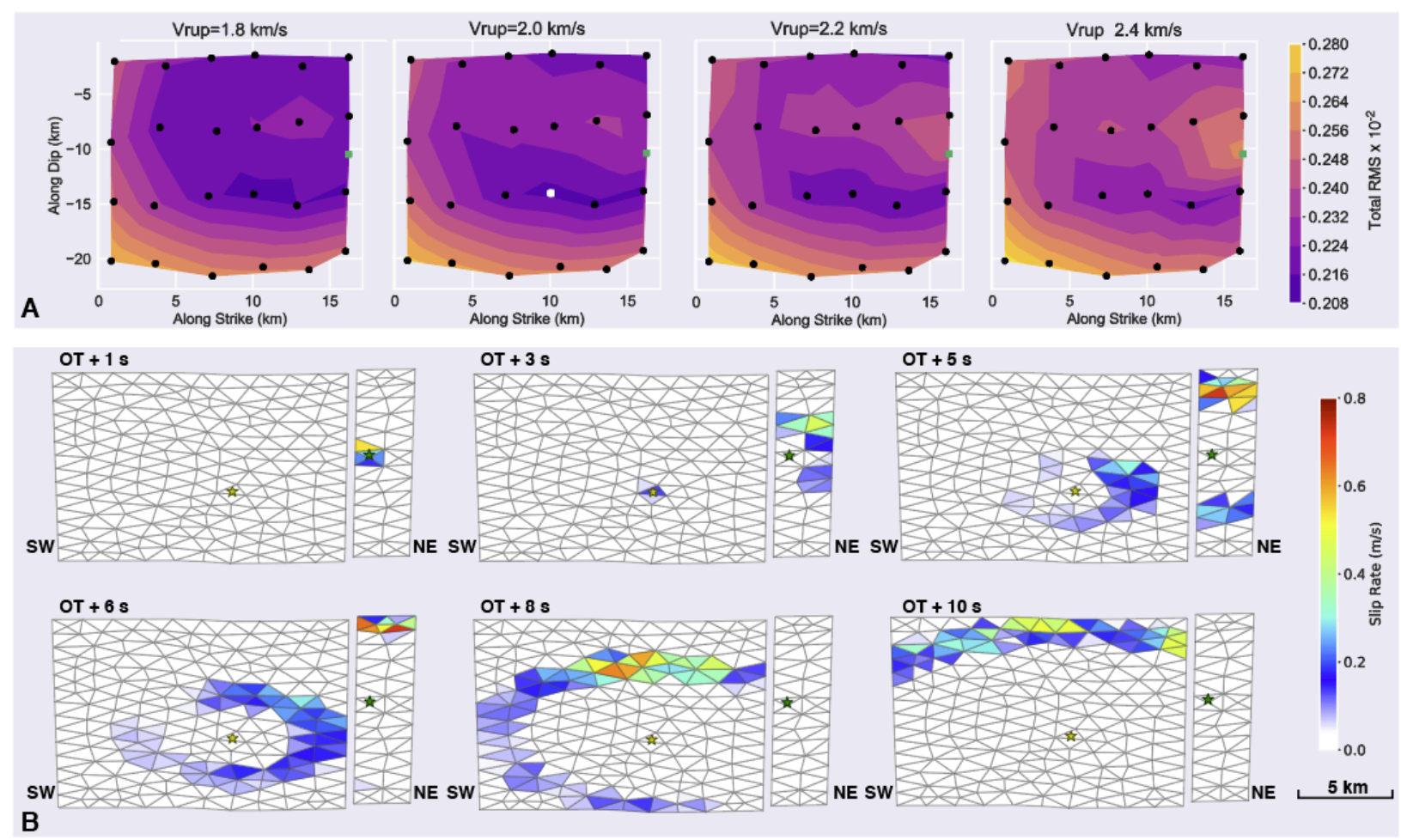

Figure 3. Evaluation of rupture propagation of the July $4 \mathrm{M}_{\mathrm{w}} 6.4$ earthquake across a stepover. A. Testing of rupture initiation location on southwest fault associated with the July $4 \mathrm{M}_{\mathrm{w}} 6.4$ event (Fault segment A in Figure 2). Total RMS for inversions of the July 4 event data only (GNSS and strong motion data, no InSAR) with prescribed maximum rupture velocities, Vrup, from $1.8-2.4 \mathrm{~km} / \mathrm{s}$ and 25 potential secondary fault initiation locations, denoted by solid squares. The green square denotes the subfault closest to the event hypocenter. The white square denotes the case with minimum total RMS. B. Snapshots of slip rate of the July $4 \mathrm{M}_{\mathrm{w}} 6.4$ event at six illustrative time frames after origin time (OT). Event hypocenter is represented by the green star, and secondary rupture initiation point is represented by yellow star.

\subsection{Coulomb Stress Change}

The slip during the $\mathrm{M}_{\mathrm{w}} 6.4$ event results in a reorganization of stress in the surrounding region. Our analysis shows a decrease in Coulomb stress on the main throughgoing fault of the $\mathrm{M}_{\mathrm{w}} 7.1$ event in the area that is cross-cut by the $M_{w} 6.4$ faults (Figure 4, fault C). Similarly, the western splay at the south end of the $M_{w} 7.1$ rupture (Figure 4, fault F), located just south of the $\mathrm{M}_{\mathrm{w}} 6.4$ fault, experienced a decrease of Coulomb stress in response to the $\mathrm{M}_{\mathrm{w}} 6.4$ slip. There is, however, a localized area of increased Coulomb stress $(<0.1 \mathrm{MPa})$ at the location of rupture initiation of the $\mathrm{M}_{\mathrm{w}} 7.1$ event. Aftershock studies demonstrate that small stress increases on this scale $(<0.1-0.3 \mathrm{MPa})$ are sufficient to bring critically stressed faults to failure [e.g. Freed, 2005]. 


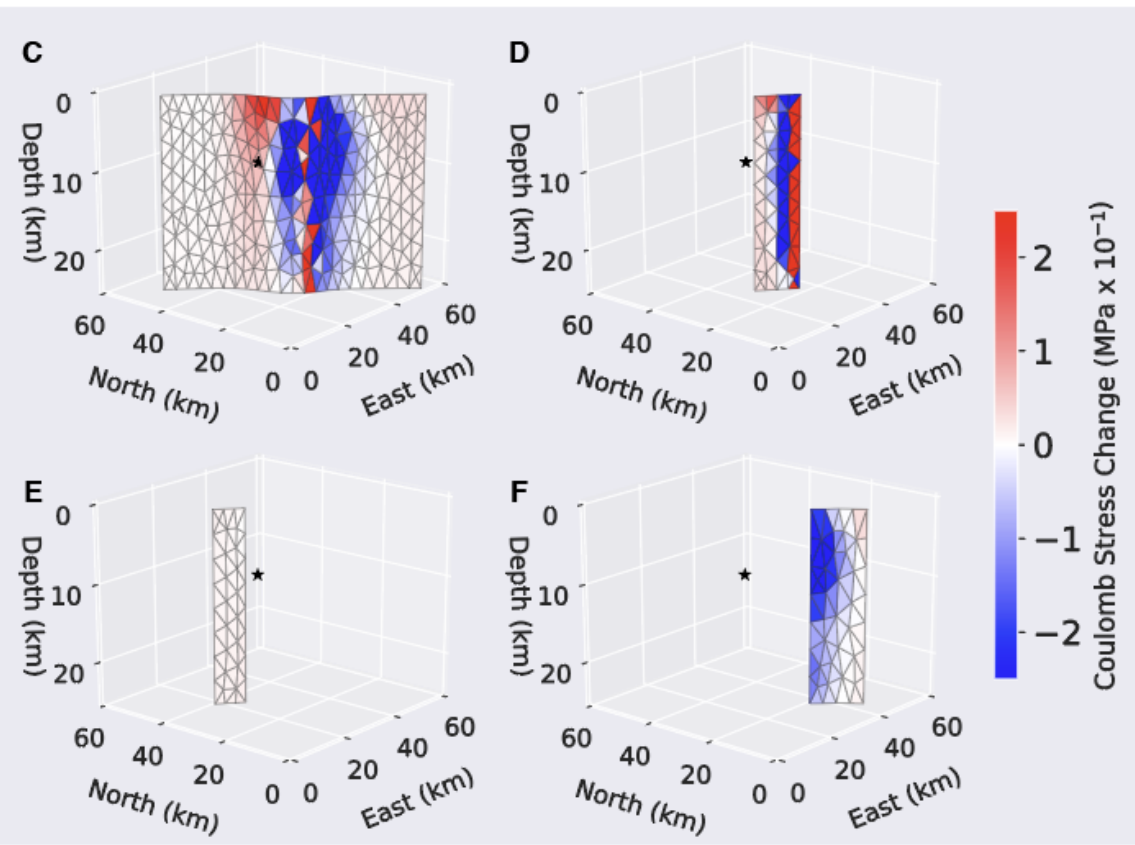

Figure 4. Coulomb stress change caused by July $4 \mathrm{M}_{\mathrm{w}} 6.4$ at faults associated with the subsequent July 6 $\mathrm{M}_{\mathrm{w}} 7.1$ (faults C-F). Black star shows the hypocenter location of the July $6 \mathrm{M}_{\mathrm{w}} 7.1$ event, located in a region of increased stress due to the July $4 \mathrm{M}_{\mathrm{w}} 6.4$ event.

\section{Discussion}

Complex, multi-fault, and slow velocity rupture appear to be common features of earthquakes in immature fault systems transitioning into major tectonic boundaries. The Ridgecrest sequence seems to display this behavior as well. Our kinematic slip inversion prefers a slow rupture velocity of $2.0 \mathrm{~km} / \mathrm{s}(\sim 55 \%$ of shear wave speed at the hypocenter depth), consistent with previous studies noted in the introduction that suggested that young faults tend to rupture slower than mature faults. We observe evidence of dynamic triggering across a $1.3 \mathrm{~km}$ stepover during the July $4 \mathrm{M}_{\mathrm{w}} 6.4$ event. Interestingly, the model prefers a case where the rupture across the stepover begins near the center of the second fault, rather than at the edge nearest the first activated fault.

From calculation of the static Coulomb stress change imposed by the July $4 M_{w} 6.4$ event, we find a heterogeneous static stress change on the fault planes associated with the subsequent July $6 M_{\mathrm{w}} 7.1$ event, wherein the hypocenter of the $\mathrm{M}_{\mathrm{w}} 7.1$ event is located directly in a localized region of increased Coulomb stress. The stress perturbation is small $(<0.1 \mathrm{MPa})$, but consistent with previous studies that demonstrate small stress changes can be sufficient to initiate rupture on critically stressed faults.

While mature faults have generally simpler geometries, incipient shear zones are often more geometrically complex, segmented, and involve multiple fault planes with variable orientations that may not be optimally oriented for failure [Crider and Peacock, 2004]. Independently, these fault strands are small and incapable of hosting large earthquakes characteristic of major plate boundary faults. Through time, these immature fault strands tend to localize deformation and ultimately link, forming throughgoing fault structures capable of hosting large magnitude earthquakes [Wesnousky, 1988; Manighetti et al., 2007; Thomas et al., 2013; Perrin et al., 2016]. The large magnitude, tectonic setting, slow rupture velocity, and structural complexity 
of the Ridgecrest sequence suggest that these events are a manifestation of the increasing contribution of the Walker Lane and ECSZ to the overall plate boundary deformation. The earthquake interactions presented here have important implications for earthquake hazard models, as small, immature faults may not be capable of hosting large magnitude earthquakes, yet cascading rupture through multiple fault strands can accommodate moderate to large magnitude earthquakes in areas where such events are unexpected.

\section{Conclusions}

We apply an innovative kinematic slip inversion approach that allows simultaneous inversion of InSAR data that spans both earthquakes alongside datasets that recorded each earthquake separately (strong motion accelerometer, HR-GNSS, and GNSS static offset) in a single inversion step. Our kinematic model is indicative of dynamic triggering across a stepover associated with the July $4 \mathrm{M}_{\mathrm{w}} 6.4$ event, and we demonstrate that the $M_{w} 6.4$ event may have statically triggered the $M_{w} 7.1$ event by increasing the Coulomb stress near the hypocenter of the $M_{w} 7.1$ earthquake. Our analysis of the kinematic rupture processes of the Ridgecrest Sequence support the concept that the Eastern California Shear Zone and Walker Lane comprise an immature, incipient fault zone, to which the San Andreas Fault is transferring an increasing amount of the overall plate motion between the Pacific and North American plates.

\section{Acknowledgments, Samples, and Data}

We thank UNAVCO for access to and maintenance of the NOTA HR-GNSS observations (https://www.unavco.org/data/gps-gnss/gps-gnss.html) and the Southern California Earthquake Data Center for access to and maintenance of the strong motion data (https://scedc.caltech.edu/research-

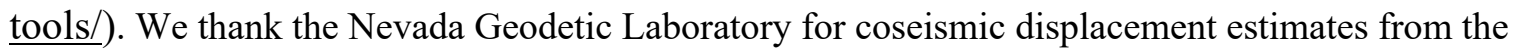
Ridgecrest events (http://geodesy.unr.edu/). We thank the European Space Agency for access to the Sentinel-1 data (https://sentinel.esa.int). Figures were made using Generic Mapping Tools [Wessel et al., 2013].

\section{References}

Atwater, T., \& Stock, J. (1998). Pacific-North America Plate Tectonics of the Neogene Southwestern United States: An Update. International Geology Review, 40(5), 375-402. https://doi.org/10.1080/00206819809465216

Bao, H., Ampuero, J.-P., Meng, L., Fielding, E. J., Liang, C., Milliner, C. W. D., ... Huang, H. (2019). Early and persistent supershear rupture of the 2018 magnitude 7.5 Palu earthquake. Nature Geoscience, 12(3), 200-205. https://doi.org/10.1038/s41561-018-0297-z

Bouchon, M., Karabulut, H., Bouin, M.-P., Schmittbuhl, J., Vallée, M., Archuleta, R., Das, S., Renard, F., \& Marsan, D. (2010). Faulting characteristics of supershear earthquakes. Tectonophysics, 493(3), 244 253. https://doi.org/https://doi.org/10.1016/j.tecto.2010.06.011

Campillo, M., \& Archuleta, R. J. (1993). A rupture model for the 28 June 1992 Landers, California, Earthquake. Geophysical Research Letters, 20(8), 647-650. https://doi.org/10.1029/92GL02822

Chen, C. W., \& Zebker, H. A. (2002). Phase unwrapping for large SAR interferograms: statistical segmentation and generalized network models. IEEE Transactions on Geoscience and Remote Sensing, 40(8), 1709-1719. https://doi.org/10.1109/TGRS.2002.802453

Crider, J. G., \& Peacock, D. C. P. (2004). Initiation of brittle faults in the upper crust: a review of field observations. Journal of Structural Geology, 26(4), 691-707. https://doi.org/https://doi.org/10.1016/j.jsg.2003.07.007 
Dokka, R. K., \& Travis, C. J. (1990). Role of the Eastern California Shear Zone in accommodating PacificNorth American Plate motion. Geophysical Research Letters, 17(9), 1323-1326. https://doi.org/10.1029/GL017i009p01323

Faulds, J. E., Henry, C. D., \& Hinz, N. H. (2005). Kinematics of the northern Walker Lane: An incipient transform fault along the Pacific-North American plate boundary. Geology, 33(6), 505-508. https://doi.org/10.1130/G21274.1

Freed, A. M. (2004). Earthquake Triggering by Static, Dynamic, and Postseismic Stress Transfer. Annual Review of Earth and Planetary Sciences, 33(1), 335-367. https://doi.org/10.1146/annurev.earth.33.092203.122505

Geng, J., Chen, X., Pan, Y., Mao, S., Li, C., Zhou, J. and Zhang, K., (2019). PRIDE PPP-AR: an opensource software for GPS PPP ambiguity resolution. GPS Solutions, 23(4), p.91.

Gomberg, J. (1996). Stress/strain changes and triggered seismicity following the Mw 7.3 Landers, California earthquake. Journal of Geophysical Research: Solid Earth, 101(B1), 751-764. https://doi.org/10.1029/95JB03251

Hill, E. M., Yue, H., Barbot, S., Lay, T., Tapponnier, P., Hermawan, I., Hubbard, J., Banerjee, P., Feng, L., Natawidjaja, D., \& Sieh, K. (2015). The 2012 Mw 8.6 Wharton Basin sequence: A cascade of great earthquakes generated by near-orthogonal, young, oceanic mantle faults. Journal of Geophysical Research: Solid Earth, 120(5), 3723-3747. https://doi.org/10.1002/2014JB011703

Hill, D. P., \& Prejean, S. (2015). Dynamic triggering. In G. Schubert (Ed.), Volume 4 of Treatise on Geophysics (Second Edition) (2nd ed., Vol. 4, pp. 273-304). https://doi.org/10.1016/B978-0-44453802-4.00078-6

Ide, S., Takeo, M., \& Yoshida, Y. (1996). Source process of the 1995 Kobe earthquake: Determination of spatio-temporal slip distribution by Bayesian modeling. Bulletin of the Seismological Society of America, 86(3), 547-566.

Ji, C., Wald, D. J., \& Helmberger, D. V. (2002). Source Description of the 1999 Hector Mine, California, Earthquake, Part I: Wavelet Domain Inversion Theory and Resolution Analysis. Bulletin of the Seismological Society of America, 92(4), 1192-1207. https://doi.org/10.1785/0120000916

King, G. C. P., \& Cocco, M. (2001). Fault interaction by elastic stress changes: New clues from earthquake sequences (R. Dmowska \& B. B. T.-A. in G. Saltzman, eds.). https://doi.org//10.1016/S00652687(00)80006-0

Lin, J., \& Stein, R. S. (2004). Stress triggering in thrust and subduction earthquakes and stress interaction between the southern San Andreas and nearby thrust and strike-slip faults. Journal of Geophysical Research: Solid Earth, 109(B2). https://doi.org/10.1029/2003JB002607

Lohman, R. B., \& Simons, M. (2005). Some thoughts on the use of InSAR data to constrain models of surface deformation: Noise structure and data downsampling. Geochemistry, Geophysics, Geosystems, 6(1). https://doi.org/10.1029/2004GC000841

Manighetti, I., Campillo, M., Bouley, S., \& Cotton, F. (2007). Earthquake scaling, fault segmentation, and structural maturity. Earth and Planetary Science Letters, 253(3), 429-438. https://doi.org/https://doi.org/10.1016/j.epsl.2006.11.004

Melgar, D., Melbourne, T. I., Crowell, B. W., Geng, J., Szeliga, W., Scrivner, C., Santillan, M., \& Goldberg, D. E. (2019). Real-time high-rate GNSS displacements: Performance demonstration during the 2019 Ridgecrest, CA Earthquakes (WWW Document). https://doi.org/10.31223/osf.io/pdxqw

Melgar, D., Fan, W., Riquelme, S., Geng, J., Liang, C., Fuentes, M., Vargas, G., Allen, R. M., Shearer, P. M., \& Fielding, E. J. (2016). Slip segmentation and slow rupture to the trench during the 2015, Mw8.3 Illapel, Chile earthquake. Geophysical Research Letters, 43(3), 961-966. https://doi.org/10.1002/2015GL067369

Melgar, D., \& Bock, Y. (2015). Kinematic earthquake source inversion and tsunami runup prediction with regional geophysical data. Journal of Geophysical Research: Solid Earth, 120(5), 3324-3349. https://doi.org/10.1002/2014JB011832 
Ozacar, A. A., \& Beck, S. L. (2004). The 2002 Denali Fault and 2001 Kunlun Fault Earthquakes: Complex Rupture Processes of Two Large Strike-Slip Events. Bulletin of the Seismological Society of America, 94(6B), S278-S292. https://doi.org/10.1785/0120040604

Perrin, C., Manighetti, I., Ampuero, J.-P., Cappa, F., \& Gaudemer, Y. (2016). Location of largest earthquake slip and fast rupture controlled by along-strike change in fault structural maturity due to fault growth. Journal of Geophysical Research: Solid Earth, 121(5), 3666-3685. https://doi.org/10.1002/2015JB012671

Peyrat, S., Olsen, K., \& Madariaga, R. (2001). Dynamic modeling of the 1992 Landers earthquake. Journal of Geophysical Research: Solid Earth, 106(B11), 26467-26482. https://doi.org/10.1029/2001JB000205

Sandwell, D.T., X. Xu, R. Mellors, M. Wei, X. Tong, and P. Wessel (2016). GMTSAR: An InSAR Processing System Based on Generic Mapping Tools (Second Edition), http://topex.ucsd.edu/gmtsar/tar/GMTSAR_2ND_TEX.pdf

Sieh, K., Jones, L., Hauksson, E., Hudnut, K., Eberhart-Phillips, D., Heaton, T., Hough, S., Hutton, K., Kanamori, H., Lilge, A., Lindvall, S., McGill, S.F., Mori, J., Rubin, C., Spotila, J.A., Stock, J., Thio, H.K., Treiman, J., Wernicke, B., \& Zachariasen, J. (1993). Near-Field Investigations of the Landers Earthquake Sequence, April to July 1992. Science, 260(5105), 171 LP - 176. https://doi.org/10.1126/science.260.5105.171

Socquet, A., Hollingsworth, J., Pathier, E., \& Bouchon, M. (2019). Evidence of supershear during the 2018 magnitude 7.5 Palu earthquake from space geodesy. Nature Geoscience, 12(3), 192-199. https://doi.org/10.1038/s41561-018-0296-0

Thomas, A. M., Bürgmann, R., \& Dreger, D. S. (2013). Incipient faulting near Lake Pillsbury, California, and the role of accessory faults in plate boundary evolution. Geology, 41(10), 1119-1122. https://doi.org/10.1130/G34588.1

Toda, S., Stein, R. S., Richards-Dinger, K., \& Bozkurt, S. B. (2005). Forecasting the evolution of seismicity in southern California: Animations built on earthquake stress transfer. Journal of Geophysical Research: Solid Earth, 110(B5). https://doi.org/10.1029/2004JB003415

Wei, S., Fielding, E., Leprince, S., Sladen, A., Avouac, J.-P., Helmberger, D., Simons, M., Hudnut, K., Herring, T., \& Briggs, R. (2011). Superficial simplicity of the 2010 El Mayor-Cucapah earthquake of Baja California in Mexico. Nature Geoscience, 4(9), 615-618. https://doi.org/10.1038/ngeo1213

Wei, S., Helmberger, D., \& Avouac, J.-P. (2013). Modeling the 2012 Wharton basin earthquakes offSumatra: Complete lithospheric failure. Journal of Geophysical Research: Solid Earth, 118(7), 35923609. https://doi.org/10.1002/jgrb.50267

Wesnousky, S. G. (1988). Seismological and structural evolution of strike-slip faults. Nature, 335(6188), 340-343. https://doi.org/10.1038/335340a0

Wessel, P., Smith, W. H. F., Scharroo, R., Luis, J., \& Wobbe, F. (2013). Generic Mapping Tools: Improved Version Released. Eos, Transactions American Geophysical Union, 94(45), 409-410. https://doi.org/10.1002/2013EO450001

Xu, X., Tong, X., Sandwell, D. T., Milliner, C. W., Dolan, J. F., Hollingsworth, J., ... \& Ayoub, F. (2016). Refining the shallow slip deficit. Geophysical Journal International, 204(3), 1867-1886.

Xu, X., Sandwell, D. T., Tymofyeyeva, E., González-Ortega, A., \& Tong, X. (2017). Tectonic and anthropogenic deformation at the Cerro Prieto geothermal step-over revealed by Sentinel-1A InSAR. IEEE Transactions on Geoscience and Remote Sensing, 55(9), 5284-5292.

Yue, H., Lay, T., \& Koper, K. D. (2012). En échelon and orthogonal fault ruptures of the 11 April 2012 great intraplate earthquakes. Nature, 490(7419), 245-249. https://doi.org/10.1038/nature11492

Zhu, L., \& Rivera, L. A. (2002). A note on the dynamic and static displacements from a point source in multilayered media. Geophysical Journal International, 148(3), 619-627. https://doi.org/10.1046/j.1365-246X.2002.01610.x 